\title{
Medical urology: a specialty long overdue. A personal view
}

The two primary functions of the bladder are storage and elimination of urine. In recent years the traditional surgical remedies for correcting symptoms associated with abnormalities of these functions have been questioned, ${ }^{1}$ and alternative non-surgical therapies advocated..$^{2-4}$ It could be further argued that all urological symptoms should initially be managed medically, particularly because co-morbidity factors are known to influence the surgical outcome. Finally, the prevalence of these symptoms is so great that surgical correction of all but the very worst would be impossible due to limited resources. In this editorial, we challenge the reflex referral of women with lower urinary tract symptoms (LUTS) to gynaecologists and men to urologists. Medical treatment is effective, non-mutilating, available to all patients irrespective of age and frailty, and can often be instigated by a specialist nurse. Initial referral to a surgeon of the patient with storage or elimination problems of the bladder is therefore misplaced and wastes valuable skills.

In this article, we argue that there is a strong case for the formation of the medical specialty of urology. There is no suggestion that surgeons treat patients with LUTS incorrectly, as they follow the lines advocated in this article, but rather that their surgical skills are not required in the majority of patients with these symptoms.

\section{Prevalence of lower urinary tract symptoms}

Although the prevalence of these symptoms, particularly incontinence, depends on the question asked, ${ }^{5}$ there can be no doubt that many people living in their own homes suffer from incontinence and would benefit from treatment. ${ }^{6}$ Many of these patients have associated co-morbidities, which would make operative treatment hazardous or at least the outcome less certain. It is known, for instance, that the prevalence of incontinence rises markedly with decreasing mobility and mental function, ${ }^{78}$ and that LUTS within institutions, particularly nursing homes for older people, are extremely common. ${ }^{9}$ The high prevalence of these symptoms alone questions the capacity of any doctor to assess and oversee initial therapy, many of which are known to be effectively improved and cured by clinical nurse specialists. ${ }^{10}$

\section{Outflow obstruction}

Patients with symptoms such as hesitancy, needing to strain, a weak stream with dribbling and a feeling of incomplete emptying are usually male. Although variable, these symptoms are usually associated with difficulty in emptying the bladder, but may also be symptoms of difficulty in storage of urine (see below). The most common cause of symptoms in these patients is benign enlargement of the prostate, which occurs in $50 \%$ of men in their fifth decade, increasing to $90 \%$ in the ninth. ${ }^{11}$ However, many men are not bothered by their symptoms or would not withstand an operation. ${ }^{12}$ There is thus no place for the knee jerk reaction of referring all men with LUTS to an urologist, who in the past frequently carried out a transurethral resection of the prostate. Present day management in surgical clinics reflects a marked move from this position towards the medical model. Many such patients, watched symptomatically and objectively over several years, do not deteriorate. ${ }^{23}$ Conservative management includes general advice (see below) and the use of drugs to relieve obstruction. Such methods are not curative and may produce only modest improvement in objective measures such as urine flow rates. However, they often relieve the bothersomeness of symptoms, therefore postponing surgery further. ${ }^{12}$. Such drugs include alphaadrenoreceptor antagonists, the newer ones of which are selective for alpha ${ }^{1}$ receptors and therefore have fewer sideeffects. Further understanding of alpha ${ }^{1}$ receptors have enabled development of even more specific drugs acting on subtypes of the alpha-receptor. ${ }^{13}{ }^{14}$ The place of 5-alphareductase inhibitors is as yet uncertain, and their cost-effectiveness unclear; drugs such as finasteride block the conversion of testosterone to dihydrotestosterone, which is 100 times more potent and more active within the prostate. Whilst there is no doubt that these drugs can reduce prostatic size, the proof that they thereby improve LUTS and objective signs of outflow obstruction in all men with symptoms is lacking. ${ }^{15} 16$ Finasteride may be more effective in those with large prostates and may make small, although statistically significant, decreases in the occurrence of acute retention and surgical interventions. ${ }^{16}{ }^{17}$

Surgical referral is recommended in patients with severe symptoms, especially if they are rapidly progressive, in those in retention or with recurrent urinary tract infections, haematuria, bladder stones or obstructive nephropathy, in men with an abnormal rectal examination or a raised prostate-specific antigen concentration, and in all patients who fail to respond to watchful waiting. ${ }^{18}$

\section{Overactivity of the detrusor muscle (unstable detrusor)}

Patients with an unstable bladder complain of urgency, frequency and urge incontinence. This is because when the detrusor muscle contracts involuntarily it threatens to, or actually overcomes, urethral resistance. It is the commonest associated condition in patients with incontinence and its prevalence rises with age. It was never a condition likely to respond to surgery although 'last ditch' enormously invasive and questionably effective operations are done for this condition. Treatment of the overactive bladder is by bladder drill which includes the use of pelvic floor muscle exercises and inhibiting the response to urgency, with or without anticholinergic therapy. ${ }^{19}{ }^{20}$ Burgio et al recently showed in a randomised controlled trial that such behavioural treatment was more effective than oxybutynin or placebo, and led to far fewer requests to change to other treatments. Oxybutynin was more effective than placebo. ${ }^{20}$ Improvements in therapy have already followed a better understanding of the clinical pharmacology and specificity of the drugs used, such as oxybutynin ${ }^{21}$ and tolterodine. ${ }^{22}$ Further advances may result from knowledge of muscarinic receptor subtypes in the bladder, and of the neurological pathways involved in continence. ${ }^{23}$ There is likely to be even more effective drug therapy in the future.

\section{Stress incontinence}

Stress incontinence is the involuntary loss of urine during physical exertion, such as coughing, sneezing, running and 
lifting. The patients are almost always women, and the symptoms are caused by weakness of the urethral sphincter with normal bladder activity. It is the least receptive condition for non-surgical treatment. Many women respond to conservative therapies and so none should be considered for surgery without a trial of these treatments. ${ }^{24}$ Patients with bleeding, pain and gynaecological pathology, including marked prolapse, need a surgical opinion. The object is to improve pelvic floor musculature sufficiently to increase the sphincteric action around the urethra and support the pelvic organs, and to improve the non-muscular closure of the urethra with oestrogens. Cure and satisfaction rates after pelvic exercises may be as high as $60-70 \%$. Such exercises have no side-effects but success depends on the correct assessment of the contraction of the pelvic muscles, and the woman's ability and determination to do them. Clear instructions and good support to improve motivation increase adherence to training, and increase the willingness to continue with home exercises for life. ${ }^{24}{ }^{25}$ Biofeedback techniques and electrical stimulation may well improve these techniques for those who cannot contract their muscles initially. Oestrogen therapy should benefit those with genuine stress incontinence because of the known effect of oestrogen on tissues around the urethral sphincter area. ${ }^{26}$ The action on the vascularity of the submucosa and the mucosa itself are likely to be particularly relevant. However, the methodology of present trials of oestrogen for stress incontinence is poor, and leaves unanswered the question whether or not oestrogen directly affects urethral sphincter closure. ${ }^{27}$ From present knowledge, it is reasonable to use oestrogen therapy in those who are known to be oestrogen-deficient. A high index of suspicion for such deficiency is appropriate in all post-menopausal women. This is backed up clinically by a history of dryness, itching, burning and dyspareunia. Examination shows a dry, smooth vaginal wall, which may be red, cracked or bleeding in severe cases. An alkaline $\mathrm{pH}$, a vaginal smear for cytology, follicle-stimulating hormone and luteinising hormone concentrations are the relevant investigations if doubt still exists. ${ }^{28}$ The success of surgery for stress incontinence depends on whether surgeons or patients are asked about the outcome, ${ }^{1}$ and is more likely in those with increased severity of symptoms pre-operatively, in younger women, and in those with no co-morbidity or obesity. Those with additional urge incontinence, anatomical problems or prolapse are unlikely to respond so well. ${ }^{29}$

\section{Retention of urine}

Complete urinary retention and incomplete bladder emptying are more commonly found in men. No symptoms confirm the diagnosis absolutely, which is defined as a post-micturition residual of $>150 \mathrm{ml}$, measured by ultrasound or single catheterisation. Outflow obstruction is

1 Black N, Griffiths J, Pope C, Bowling A, Abel P. Impact of surgery for stress incontinence on morbidity: cohort study. BMF 1997;315:1493-8.

2 Lee AJ, Russell EBAW, Garraway WM, Prescott RJ. The three year follow-up of a community-based cohort of men with untreated benign prostatic hyperplasia. Eur Urol 1996;30:11-7.

3 Abrams P. Managing lower urinary tract symptoms in older men. BMF 1995;310:1113-7.

4 Macfarlane GJ, Sangnier PP, Richard F, Teillac P, Botto H, Boyle P. Determinants of treatment-seeking behaviour for urinary symptoms in older men. Brf Urol 1995;76:714-8.

5 Castleden CM. Incontinence-still a geriatric giant? Age Ageing 1997;26(S4): $47-52$.

6 Brittain KR, Peet SM, Castleden CM. Stroke and incontinence. Stroke 1998;29:524-8.

7 McGrother CW, Jagger C, Clarke M, Castleden CM. Handicaps associated with incontinence: implications for management. $\mathcal{F}$ Epidemiol Community Health 1990;44:246-8.

8 Resnick NM. Geriatric incontinence. Urol Clin N Am 1996;23:55-74. the commonest cause of retention, but poor detrusor function, particularly in older people, also occurs. Drugs, neurological conditions, and the results of surgery all cause retention. The treatment obviously depends on the cause but whatever it is, immediate catheterisation is necessary. Subacute or long-term catheterisation is better carried out on an intermittent self- or carer basis. ${ }^{30} \mathrm{~A}$ suprapubic catheter may be better than a long-term indwelling urethral catheter, because of less leakage, trauma and infection. It is easier to change, and can be maintained with a higher standard of personal hygiene.

\section{'Transient' causes of LUTS}

'Transient' causes of LUTS are usually precipitators which aggravate underlying pathology rather than absolute causes such as those discussed above. This category includes urinary tract infections, drug therapy, increased urinary solute load (glycosuria or hypercalcaemia), oestrogen deficiency, psychiatric conditions such as depression or confusion, lack of mobility, inappropriate fluid intake and overloading of the bowel. ${ }^{8}$ All of these conditions respond only to nonsurgical therapy. They need exclusion in every patient with LUTS.

\section{General advice}

Many dietary factors may play a role in either the pathogenesis or the resolution of incontinence. Although published evidence for effect is minimal, they are acceptable as general good advice, increase the well being of sufferers and do no harm. Factors in this category also include weight loss, stopping smoking, caffeine consumption, fluid intake (both excessive and restrictive approximately 1.51 per day is advised), and the relief of constipation. Perineal hygiene which includes a soapy wash once daily is also beneficial, and is largely overlooked by healthcare professionals.

\section{Co-morbidity problems}

Because LUTS increase with age and disability, many patients have co-morbid conditions, which require treatment in their own right. These conditions are largely medical, or require careful medical assessment.

C M CASTLEDEN HILARY M DUFFIN Continence Clinic, Leicester General Hospital, Gwendolen Road, Leicester LE5 4PW, UK

Submitted 3 February 1999

Accepted 13 August 1999

Keywords: urology; unstable detrusor; stress incontinence; retention of urine

9 Peet SM, Castleden CM, McGrother CW. Prevalence of urinary and faecal incontinence in hospitals and residential and nursing homes for older people. BM7 1995;311:1063-4

10 O'Brian J, Austin M, Sethi P, O'Boyle P. Urinary incontinence: prevalence, need for treatment and effectiveness of intervention by a nurse. BMF 1991; 303:1308-12.

11 Berry SJ, Coffy DS, Walsh PC, Ewing LL. The development of human benign prostatic hyperplasia with age. F Urol 1984;1332:474-9.

12 Assassa RP, Osborn DE, Castleden CM. Male urinary tract symptoms: is surgery always necessary? Gerontology 1998;44:61-6.

13 Roehrborn CG. Rationale for the inclusion of alpha- adrenergic blockade in benign prostatic hyperplasia treatment guidelines. Eur Urol 1996;29(suppl 1):40-8.

14 Chapple CR, Wyndaele JJ, Nording J, Boeminghaus F, Ypma A, Abrams P. Tamsulosin, the first prostate-selective alpha 1A adrenoceptor antagonist. Eur Urol 1996;29:155-67.

15 Lepor H, Williford WO, Barry MJ, et al. The efficacy of terazosin, finasteride, or both in benign prostatic hyperplasia. N Engl f Med 1996;335: 533-9. 
16 Boyle P, Gould L, Roehrborn CG. Prostate volume predicts outcome of treatment of benign prostatic hyperplasia with finasteride: meta- analysis of randomized clinical trials. Urology 1996;48:398-405.

17 Andersen JT, Nickel JC, Marshall VR, Schulman CC, Boyle P. Finasteride significantly reduces acute urinary retention and need for surgery in patient with symptomatic benign prostatic hyperplasia. Urology 1997;49:839-45.

18 Bullock N. Benign prostatic hyperplasia. Prescribers f 1999;39:9-15

19 Burgio KL, Locher JL, Goode PS, et al. Behavioral vs drug treatment for urge urinary incontinence in older women. $7 A M A$ 1998;280:1995-2000.

20 Iqbal P, Castleden CM. Management of urinary incontinence in the elderly. Gerontology 1997;43:151-7.

21 Yarker YE, Goa KL, Fitton A. Oxybutynin. A review of its pharmacodynamic and pharmacokinetic properties, and its therapeutic use in detrusor instability. Drugs Aging 1995;6:243-62.

22 Nilvebrant L, Hallen B, Larsson G. Tolterodine-a new bladder selective muscarinic receptor antagonist: preclinical pharmacological and clinical

23 De Groat WC. Neuroanatomy and neurophysiology: innervation of the lower urinary tract. In: Ras S, ed. Female urology, 2nd edn. Philadelphia: WB Sanders, 1998; pp28-42.
24 Berghmans LCM, Hendriks HJM, Bo K, Hay-Smith EJ, de Bie RA, van Waalwijk van Doorn ESC. Conservative treatment of stress urinary incontinence in women: a systematic review of randomised clinical trials. $\mathrm{Br} \mathcal{F}$ Uro 1998;82:181-91.

25 Bo K, Talseth T, Holme I. Single blind randomised controlled trial of pelvic floor exercises, electrical stimulation, vaginal cones and no treatment in the management of genuine stress incontinence in women. BMf 1999;318:48793.

26 Miodrag A, Castleden CM, Vallance TR. Sex hormones and the female urinary tract. Drugs 1988;36:491-504.

27 Fantl JA, Bump RC, Robinson D, et al. Efficacy of estrogen supplements in the treatment of urinary incontinence. Obstet Gynecol 1996;88:745-9.

28 Mettler L, Olsen PG. Longterm treatment of atrophic vaginitis with low-dose oestradiol vaginal tablets. Maturitas 1991;14:23-31.

29 Hutchings A, Griffith J, Black NA. Surgery for stress incontinence: factors associated with a successful outcome. Br F Urol 1998;82:634-43.

30 Duffin HM. Clean intermittent self-catherisation. $\mathcal{f}$ Community Nurs 1996; 10:18-20

Thomas Willis (1621-75) was born in Great Bedwyn, Wiltshire, son of a Royalist farmer. He became professor of natural philosophy at Oxford (1660-75) and a physician of great repute in Westminster. He was one of the founders of the Royal Society (1662). He is immortalised in the circle of Willis, arterial anastomoses at the base of the brain. In his classic Celebri Anatome (1664) the copper plates were by Christopher Wren. A commemorative plaque was placed at his birthplace on 14 May 1994. - D G James 